\title{
Potential number of tooth losses in clicking, popping and crepitation of Temporomandibular Disorders (TMD) in elderly
}

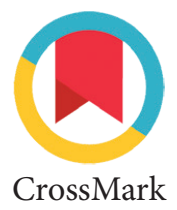

\author{
Elfrida M. Agustina, ${ }^{1}$ Zahreni Hamzah, ${ }^{1 *}$ Zainul Cholid $^{2}$
}

\section{Abstract}

Objective: Clicking, popping, and crepitation is the most common symptom of Temporomandibular Disorders (TMD). TMD can be caused by tooth loss, and tooth loss is widespread among the elderly.

Material and Methods: This research is using a correlational analysis with a cross-sectional study approach. Tooth loss was divided into six regions ( $R 1, R 2, R 3, R 4, R 5, R 6)$ and joint sounds were divided into four categories (clicking, popping, crepitation, normal).
Result: Multinomial logistic regression analysis test for overall tooth loss showed a p-value of 0.000 in clicking and crepitation, and for popping, it has a $p$-value of 0.248 . The results of tests on six regions of tooth loss obtained a p-value of 0.017 at R1 for clicking sound and p-value of 0.014 at R2 for crepitation. This showed that clicking and crepitation had a significant correlation with the amount of tooth loss $(p<0.05)$.

Conclusion: The amount of tooth loss has a significant relationship with clicking and crepitation of Temporomandibular Joint (TMJ).
${ }^{1}$ Department of Biomedical Physiology Laboratory, Faculty of Dentistry/Universitas Jember, Jember, Indonesia

${ }^{2}$ Department of Oral Surgery, Faculty of Dentistry/Universitas Jember, Jember, Indonesia

*Correspondence to:

Zahreni Hamzah, Department of Biomedical Physiology Laboratory, Faculty of Dentistry/Universitas Jember, Jember, Indonesia zahreni.fkg@unej.ac.id

Received: 29 0ctober 2019 Revised: 5 December 2019 Accepted: 9 November 2020 Available Online: 1 December 2020

Keywords: Cicking, Crepitation, Elderly, Number of tooth loss, Popping

Cite this Article: Agustina EM, Hamzah Z, Cholid Z. 2020. Potential number of tooth losses in clicking, popping and crepitation of Temporomandibular Disorders (TMD) in elderly. Journal of Dentomaxillofacial Science 5(3): 185-190. D0I: 10.15562/jdmfs.v5i3.1078

\section{Introduction}

The aging process makes people generally have a decreased ability to resolution, regenerate, and repair cells and tissues. The aging process affects the periodontal tissue and teeth so that it can cause tooth loss. ${ }^{1}$ Tooth loss is one of the main problems in oral health. The main causes of tooth loss, in general, are caries and periodontal disease. Loss of teeth who not replaced with dentures can cause the remaining teeth to migrate or rotate and if not replaced for a long time will accelerate degenerative diseases in the Temporomandibular Joint (TMJ). ${ }^{2}$ Edentulous or partial tooth loss is known to be widespread in the elderly. ${ }^{3}$

Tooth loss will cause loss of occlusal support. Loss of occlusal support is one of the factors causing degenerative changes in TMJ. Tooth loss can cause damage to TMJ such as the resorption of the articular eminence and the occurrence of disc displacement. ${ }^{4}$

Temporomandibular Disorders (TMD) has several signs and symptoms. The most common symptom of TMD is joint sound. ${ }^{5}$ Clicking followed by crepitation and popping is the most common sound symptom that arises of TMD. ${ }^{6}$ Clicking sounds are used to describe small and single sounds and can only be heard by sufferers while popping sounds are used to describe explosions or sharp popping sounds so that popping sounds can be heard by people near the sufferer because it is a louder voice. ${ }^{7}$ Crepitus sound indicates a specific defect on the articulation surface of the joints. It will make a sound when the movement of the articular disc passes through an uneven articular surface. $^{8}$ Crepitation will make multiple or crackling noises during the opening and closing of the mandible. Crepitation is also associated with articular surface disorders that often occur in patients with osteoarthrotis. ${ }^{9}$ TMD can affect masticatory muscles, TMJ itself, and surrounding structures so that it can change the performance of the functions of the stomatognathic system such as chewing and speaking. ${ }^{10}$

Based on the elaboration above, the purpose of this study was to determine the relationship between the amount of tooth loss and TMJ noise in the elderly. From these results, it is expected to provide information on the causes of TMJ noise with tooth loss. So that in the future can anticipate the occurrence of TMD due to tooth loss in the elderly group.

\section{Material and Methods}

This type of research is correlational analysis, with a cross-sectional study approach. This research was conducted in four villages representing the Jember district, namely Puger Wetan village, Puger 
sub-district, Sucopangepok village, Jelbuk subdistrict, Kebonsari village, Sumbersari sub-district, and Sumberagung village, Sumberbaru sub-district. The four villages in this study were randomly selected based on the location of the village which included mountains, coasts, agriculture, and cities. Data collection was carried out at Karang Werda in each selected village. The population of this study is the elderly aged 45 years and over, which are divided into three categories, namely age between 45-59 years old (middle age), age between $60-74$ years old (elderly), and age $\geq 75$ years old (old), the category follows the WHO classification of elderly.

Respondents in this research are taken using a purposive sampling technique. The included respondents are those who have one or more missing teeth and are not replaced with dentures. The number of research subjects is using total sampling. The procedure is carried out by checking the amount of tooth loss using a basic instrument and then proceeding by checking the TMJ sound using a stethoscope on the anterior right and left sides of the meatus in turn. The amount of tooth loss was divided into six regions namely, R1 (right maxillary posterior region), R2 (maxillary anterior region), R3 (left maxillary posterior region), R4 (left mandibular posterior region), R5 (mandibular anterior region), R6 (right mandibular posterior region) and the types of joint sounds are divided into four categories who given scoring namely, clicking (score 1), popping (score 2), crepitation (score 3), and normal (score 0 ). The data obtained were analyzed using multinomial logistic regression analysis with a significance value $(\alpha)$ of 0.05 .

\section{Results}

The total respondents obtained in this study were 113 elderly respondents. Respondents aged between 60-74 years old are the most obtained age category, with a percentage of $56.6 \%$. Respondents aged between 45-59 years old had a percentage

Table 1 Characteristics of respondents

\begin{tabular}{|c|c|c|c|}
\hline \multirow{2}{*}{ Age } & \multicolumn{2}{|c|}{ Gender } & \multirow[b]{2}{*}{ 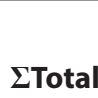 } \\
\hline & ¿Male & $\Sigma$ Female & \\
\hline $45-59$ & 2 & 35 & 37 \\
\hline $60-74$ & 9 & 55 & 64 \\
\hline$\geq 75$ & 6 & 6 & 12 \\
\hline Total & 17 & 96 & 113 \\
\hline
\end{tabular}

had a percentage of $10.6 \%$. While the distribution of respondents by gender found that respondents with female sex were dominated by a percentage of $85 \%$, while male respondents had a percentage of $15 \%$ table 1.

The result showed an increase in the average of tooth loss with age. The average tooth loss experienced by respondents by successive age category was $8.38 \pm 6.45 ; 11.23 \pm 8.66 ; 16.33 \pm 7.6$ for ages between $45-59$ years old, ages between $60-74$ years old, and ages $\geq 75$ years old. However, respondents with tooth loss did not always experience TMJ noise. Respondents numbered 47 respondents from 113 respondents with tooth loss who did not experience TMJ noise. Types of joint clicking were found in 33 respondents while popping sound types were only found in two respondents and crepitations were found in 12 respondents figure 1.

There are differences in the average of tooth loss in males and females. The average number of teeth loss was more experienced by male elderly respondents $(11.59 \pm 9.29)$ than females $(10.71 \pm 7.99)$, but TMJ noise was mostly found in the female elderly $(78.7 \%)$. The distribution of joint sound disorders by gender can be seen in figure 2 .

The amount of tooth loss was divided into six regions to determine the location of the region that most affected by the TMJ sound. The average of tooth loss in the six regions can be seen in table 2. Clicking and crepitation have a higher average of tooth loss in each region compared to normal and popping. Joint popping sounds were only found in two respondents so that they had a lower average table 2.

The loss of first molars was found in almost all respondents. Clicking and crepitation have a high percentage of loss of first molars and spread to all regions. Respondents with popping sound had a $100 \%$ percent losing of first molar in the left mandibular posterior region (R4) because the popping sound was only owned by two respondents and both respondents experienced the loss of first molar on R4 figure 3.

There are 19 respondents experienced joint sound on one side only. Which is 15 of the respondents had a clicking sound and the remaining four experienced crepitations. The 19 respondents constituted $40.4 \%$ of all respondents with joint sound. A joint sound that occurs only on one side can occur due to bad habits committed by the respondent. $73.7 \%$ of respondents with joint sound disorders on one side have the habit of chewing on one side and $63.2 \%$ of respondents have the habit of sleeping on one side figure 4 . 
Table 2 The average of tooth loss in six regions according to joint sound

\begin{tabular}{lcccccc}
\hline & \multicolumn{5}{c}{ The Average of Tooth Loss } \\
\hline Joint Sound & $\mathbf{R 1}$ & $\mathbf{R 2}$ & $\mathbf{R 3}$ & $\mathbf{R 4}$ & $\mathbf{R}$ & $\mathbf{R}$ \\
\hline Clicking & $2.7 \pm 1.13$ & $2.42 \pm 2.37$ & $2.52 \pm 1.37$ & $2.79 \pm 1.11$ & $2.0 \pm 2.36$ \\
Popping & $0.5 \pm 0.71$ & 0 & $0.5 \pm 0.71$ & $1.5 \pm 0.71$ & 0 & $2.79 \pm 1.14$ \\
Crepitation & $3.0 \pm 1.3$ & $4.7 \pm 2.2$ & $3.3 \pm 1.0$ & $3.2 \pm 1.3$ & $3.3 \pm 2.7$ \\
Normal & $1.33 \pm 1.11$ & $0.68 \pm 1.33$ & $1.41 \pm 1.19$ & $1.64 \pm 1.13$ & $0.52 \pm 1.27$ & $3.3 \pm 1.1$ \\
\hline
\end{tabular}

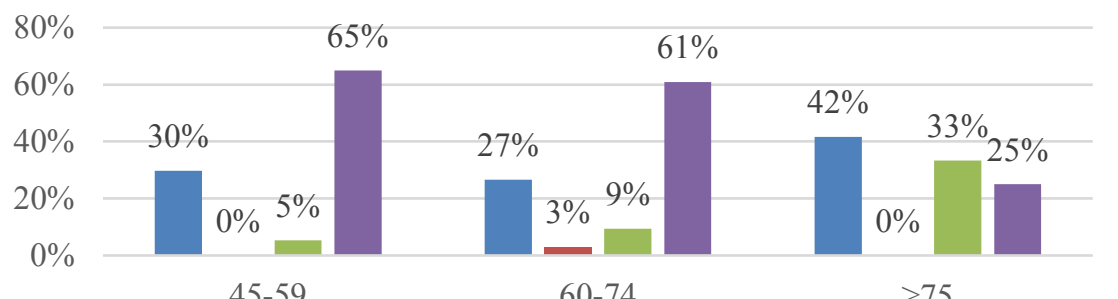

60-74 $\geq 75$

-Clicking $\square$ Popping Crepitation $\square$ Normal

Figure 1 Distribution of respondents with TMJ sound

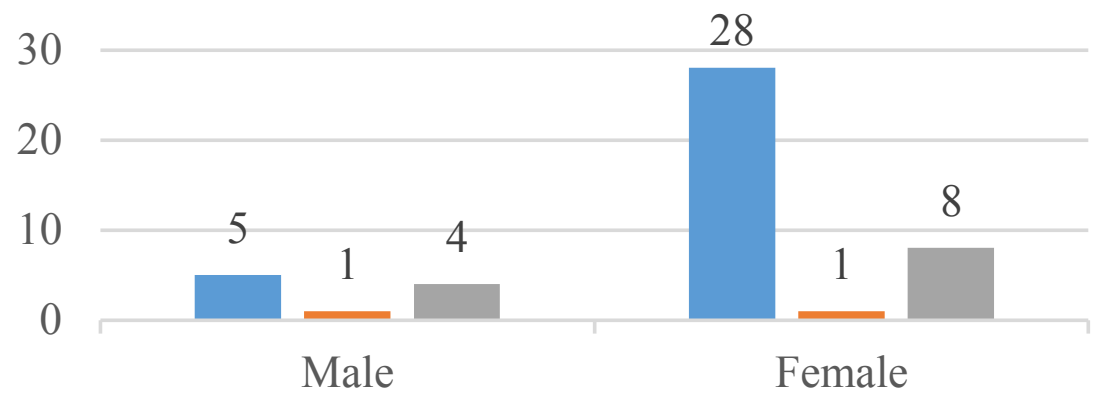

-Clicking $\quad$ Popping $\square$ Crepitation

Figure 2 Distribution of sound of TMJ by gender

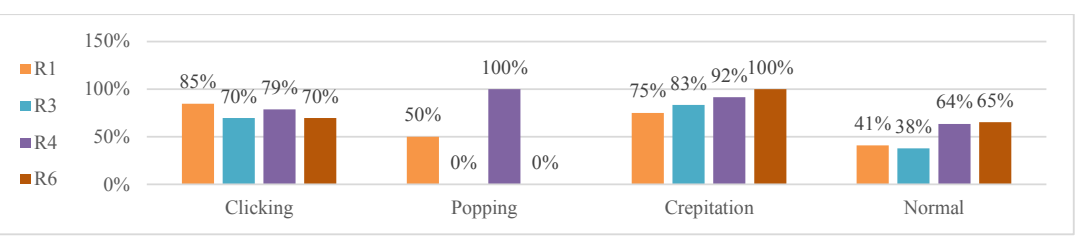

Figure 3 The percentage of losing first molars

20

0

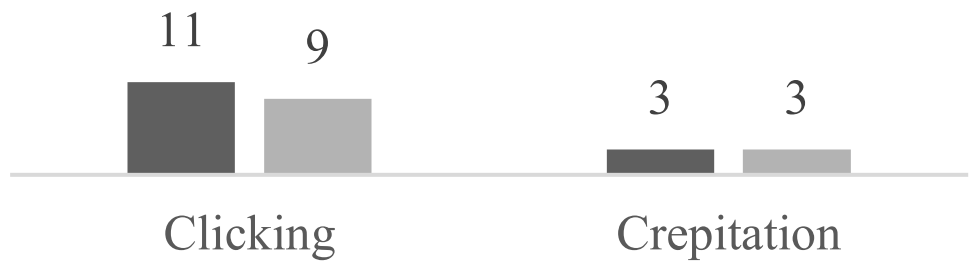

Chewing on one side $\quad$ Sleeping on one side

Figure 4 TMJ sound on one side only

\section{Discussion}

Elderly aged between 60-74 years old are the most commonly found elderly as respondents. The small number of respondents aged between 45-59 years old compared to those of 60-75 years old may be due to respondents of that age being unable to attend Karang Werda because according to BPS data in Jember 2019, it is stated that residents with less than 65 years old of age are still residents of productive age. Elderly respondents aged 75 years old and over are the least found respondents. The small number of respondents at this age can be caused by the relationship between functional limitations and aging, by increasing age then decreasing one's mobility such as the ability to stand or walk, causing limitations in the elderly in visiting health facilities or Karang Werda. ${ }^{11,12}$

Female elderly were found to be dominant as respondents in this study. BPS data for Jember 2018 shows that the number of the female population is higher than the male population with a sex ratio of $96.69 \%$ which means that from 100 female population, there are 96-97 male population. Another reason that can be given is that the activeness of women is higher than men. By research conducted by Intarti et al. ${ }^{15}$ which says that elderly women are more diligent in finding information and solutions for health problems in old age so that they will be more concerned about the health condition of the body than older men. ${ }^{13}$

The results showed that the average tooth loss increased with age. Research by Natto et al..$^{14}$ states that age has a significant effect on the incidence of tooth loss. The aging process causes changes in soft tissue and hard tissue. ${ }^{14}$ The aging process has an impact on dental and oral hygiene including increasing dental caries and periodontal disease. Dental caries and periodontal disease that continues and is not treated, over time there will be a decrease in alveolar bone density that causes tooth loss. ${ }^{15}$

In this study, the average of teeth lost by male respondents was higher than female respondents. The higher number of teeth lost in men in this study may have been due to the low oral hygiene 
awareness factor in men. The data results showed that more men elderly respondents brushed their teeth less than twice a day than women elderly respondents. The number of men respondents who did not brush their teeth was also higher than the women respondents in percentage. This shows that awareness of oral hygiene is more owned by women than men, thereby increasing the risk of tooth loss in men. ${ }^{16}$

Tooth loss in the elderly causes them to have to adjust the new functional mastication with the remaining teeth. Adjustment of new functional chewing can cause changes in the trajectory of the TMJ movement. ${ }^{17}$ In normal joint movement, the disc is located directly on the head of the condyle. The articular disc will be between the mandibular condyle and the posterior slope of the articular eminence in the normal functional state when the jaw closes. The condyle along with the articular disc will rotate and translate at the same time when opening the mouth in the normal functional state towards the anterior articular eminence. ${ }^{18}$ Tooth loss will cause overload on the TMJ. Chronic overload on the TMJ will cause degenerative changes on the articular surface and can cause displacement of the disc. ${ }^{19}$ Anterior disc displacement is the most common displacement. Displacement of the disc to the anterior causes when opening the mouth, the condyle moves forward pushing the disc anteriorly resulting in a fold of the disc. In a situation where the disc cannot be pushed anymore, the condyle will jump over the fold and continue to move below the surface of the disc. This jump will cause a clicking or popping sound. ${ }^{20}$

Clicking noise is a joint sound disorder that is most commonly found in this study. Statistical test results on overall tooth loss showed that the amount of tooth loss affected the clicking joint sound $(\mathrm{p}<\alpha)$. Clicking increases the incidence as the number of teeth decreases. Tooth loss causes tooth changes such as migration and rotation of the remaining teeth, causing dental malposition. Dental malposition will cause occlusion to be out of harmony and occlusal disharmony occurs. Occlusal disharmony causes differences in centric occlusion and centric relations which results in the occurrence of TMJ abnormalities. This will cause changes in the position of the articular disc which results in the clicking sound. ${ }^{20}$

Respondents with clicking sound had a greater mean loss of posterior teeth than anterior teeth. Tooth loss in the posterior dental arch has been considered a risk factor for structural changes in the TMJ. The loss of posterior tooth support will cause a reduction in the vertical dimension of the occlusion so that it will overload the TMJ excessively and cause internal derangement. ${ }^{21}$ Reduction in vertical dimensions causes the anterior disc displacement. Displacement of the disc to the anterior will cause clicking when opening or closing the mouth. ${ }^{20}$ Statistical tests also showed that the amount of posterior tooth loss was associated with clicking sound $(\mathrm{p}<\alpha)$. Respondents with the clicking sound category had the highest percentage of loss the first right maxillary molar (R1). The loss of the molar tooth has been considered as an etiological factor for TMD. ${ }^{22}$ Loss of the first molar can cause joint noise. Research by Dwpayanti et al. ${ }^{23}$ states that loss of molar teeth is one of the factors initiating lesions in the load-bearing the articular surfaces of the condyle and articular individuals. ${ }^{23}$

Statistical test results on tooth loss in six regions showed that the amount of tooth loss in R1 affected the type of clicking joint sound. R1 is placed in the right maxillary posterior and has an average tooth loss which is quite high compared to other regions, but the average tooth loss on R1 is not the highest average tooth loss compared to other regions. However, in the clicking sound category, the right maxillary posterior region (R1) has the highest percentage for loss of first molar teeth.

Statistical test results in the popping category with the number of tooth loss in six regions showed that the number of tooth loss in each region did not affect the type of popping joint sound. This might have happened because the popping sound was only found in two respondents so that the results were less representative. Nonetheless, respondents with popping sound had some tooth loss in the posterior region and did not experience tooth loss in the anterior region. Posterior tooth loss experienced by respondents is in each of the two posterior regions and three posterior regions. This is consistent with research by Al-Sharafi et al. ${ }^{22}$ which shows that respondents with fewer posterior teeth lost in the higher quadrant have a higher prevalence of TMD than respondents with more posterior teeth remaining in fewer quadrants. ${ }^{22}$ Respondents with popping sound also have a loss of first molar teeth on R1 and R4.

Crepitation is found to increase with age and with an increase in the average of tooth loss. Crepitation is usually found in many elderly people, this happens because crepitation is usually associated with changes in degeneration due to aging. ${ }^{20}$ Changes in degeneration occur on the articular surface with increasing age due to intense daily use. $^{24}$ The average tooth loss in all regions in the crepitation category showed the highest value compared to other categories. This shows that respondents with the crepitated sound disorder have the least remaining teeth compared to other 
respondents so that the few remaining teeth will receive a heavier burden than the remaining teeth owned by other respondents. Statistical test results also showed that the amount of tooth loss affected crepitated joint sounds $(p<\alpha)$.

Statistical tests of tooth loss in six regions showed that the amount of tooth loss in R2 affected the type of joint crepitation. $\mathrm{R} 2$ is the anterior region of the maxilla and has the highest amount of tooth loss compared to other regions. The anterior teeth play a role in determining the movement of the mandible so that loss of the anterior teeth will cause changes in the pattern of mandibular movement. The direction of the anterior teeth in the movement of the mandible is in harmony with the pattern of movement of the TMJ. Changes in the direction of the anterior teeth will have an indirect effect on the health of the TMJ. ${ }^{25,26}$ Nevertheless, Tallents et al..$^{27}$ reported that posterior tooth loss of the mandible can accelerate the progression of degenerative joint disease. ${ }^{27}$ Respondents with crepitation sound had higher average of tooth loss in mandibular posterior teeth (R4 and R6) than the maxillary posterior region. Respondents with crepitation also had the highest percentage of loss of first molars in the lower right posterior region (R6). Osteoarthrosis is one of the degenerative joint diseases on the articular surface that is often found in the elderly. ${ }^{17}$ Manchikalapudi et al. ${ }^{28}$ in his study stated that the loss of support in posterior teeth is also considered to significantly increase the risk of osteoarthrosis. Osteoarthrosis has an uneven articular surface appearance due to fibration, erosion, and cracks in the superficial layer of cartilage in the TMJ. ${ }^{28,29}$ Wiese et $\mathrm{al} .{ }^{30}$ concluded that crepitation is often accompanied by osseous changes in the joints, such as flattening, erosion, osteophytes, and sclerosis. ${ }^{30,31}$ Crepitation can occur due to the presence of rough and irregular articulation surfaces in the joints, causing compound sounds that can be observed during mandibular movements.

Joint sound is most commonly owned by female respondents. Research by Bueno et al. ${ }^{32}$ states that the possibility of this happening is due to the factor of a higher level of work stress for women. These things can cause depression. Depression affects women almost twice more often than men. Patients with depression are at high risk of developing TMD. ${ }^{32}$ Emotional stress can cause muscle hyperactivity, which is bruxism or clenching so that when the emotional component is associated with physical factors, such as occlusal changes, stress relief by the stomatognathic system produces symptoms of pain and dysfunction..$^{33}$ However, in this study, no data was obtained about stress on respondents.
TMJ sound can occur on one side or both sides of the joint. There are $40.4 \%$ of respondents with TMD experience sound disorders only on one side of the joint. Disruption on one side of the joint can occur if there is a unilateral loss of the molar teeth. Joint sounds will occur in the opposite direction to tooth loss. This is called adaptive remodeling or compensatory adaptation of the condyle as opposed to changes in occlusion. ${ }^{34}$ However, in this study, no significant relationship was found between the two matters. Joint sound on one side of the joint may be caused because most respondents who experience this disorder have the habit of chewing on one side and sleeping on one side. Chewing on one side and side sleeping habits cause the condyle to receive excessive pressure on one side. Balanced tooth contact on both sides of the jaw will make the mandible position stable so that the biomechanical pressure that will be transmitted towards both sides of the joint will also be balanced. Chewing on one side and sleeping on their side causes the mandibular condition to become unstable. Sleeping on an oblique position can cause joint imbalance because the patient constantly positions the condyle in the inferoanterior region and the masticatory muscles in a position of continuous contraction. This will result in excess biomechanical pressure on one side of the joint and damage to the joint structure can occur. ${ }^{35,36}$

\section{Conclusion}

The amount of tooth loss has a significant relationship with clicking and crepitation of the TMJ. The amount of tooth loss is not associated with popping sound because the popping cases found in the study are very small that the results obtained are less representative.

\section{Acknowledgment}

Thank you for Department of Biomedical Physiology Laboratory and Department of Oral Surgery, Faculty of Dentistry/Universitas Jember.

\section{Conflict of Interest}

The authors report no conflict of interest.

\section{References}

1. Melati CA, Susilawati S, Rikmasari R. An overview of the quality of life of elderly patients using removable dentures in Dental Medicine Padjadjaran University. Majalah Kedokteran Gigi Indonesia 2017;3: 133-138. (In Indonesia)

2. Srivastava V, Dutt $P$, Chand $P$, et al. Factors related to tooth loss among population: a cross-sectional study. Int J App Dent Sci 2018;4: 31-33. 
3. De-Medeiros AKB, Campos MDfTP, Costa RSGDs, et al. Improvement in quality of life of elderly edentulous patients with new complete dentures: a systematic review. Int J Prostho 2019;32: 272-277.

4. Chiang MT, Li TI, Yeh HW, et al. Evaluation of missing-tooth effect on articular eminence inclination of temporomandibular joint. J Dent Sci 2015;10: 383-387.

5. Kaushal P, Saha MK, Pandey P, et al. Prevalence of temporomandibular disorders in dental students: a survey in Indore city. Int J Appl Dent Sci 2018;4: 273-277.

6. Gopal KS, Shankar R, Vardhan HB. Prevalence of temporo-mandibular joint disorders in symptomatic and asymptomatic patients. A cross-sectional study. Int J Adv Sci 2014;1: 14-20.

7. Song SJ, Park $\mathrm{CH}$, Liang $\mathrm{H}$, et al. Noise around the knee. Clin Orthop Surg 2018;10: 1-8.

8. Suhartini. Temporomandibular Joint (TMJ) abnormalities. Stomatig 2011;8: 78-85. (In Indonesia)

9. Robert L, Gauer MD, Michael J, et al. Diagnosis and treatment of temporomandibular disorders. Am Fam Physic 2015;91: 378-386.

10. Rovida TASR, Prado RLdP, Joaquim RC, et al. Elderly caregivers at long-stay institutions: quality of life and temporomandibular dysfunction. Braz J Oral Sci 2015;14: 204-208.

11. Satariano WA, Guralnik JM, Jackson RJ, et al. Mobility and aging: new direction for public health action. Framing health matters. Am J Public Health 2012;102: 1508-1515.

12. Grimmer M, Riener R, Walsh CJ, et al. Mobility related physical and functionallosses due to aging and disease a motivationfor lower limb exoskeletons. J Neuroeng Rehabilitation 2019;16: 1-21.

13. Intarti WD, Khoriah SN. Factors that influence the use of posyandu for the elderly. J Health Stud 2018;2: 110-122. (In Indonesia)

14. Natto ZS, Aladmawy M, Alasqah M, et al. Factors contributing to tooth loss among the elderly: a cross sectional study. Singapore Dent J 2014;35: 17-22.

15. Tiwari T, Scarbro S, Bryant LL, et al. Factors associated with tooth loss in older adults in Rural Colorado. J Community Health 2016;41: 476-481.

16. Russel SL, Gordon S, Kaste LM. Sex/gender differences in tooth loss and edentulism. Historical perspectives, biological factors, and sociologic reasons. Dent Clin North Am 2013;57: 317-337.

17. Al-Shumailan Y, Al-Jabrah O, Al-Shammout R, et al. The prevalence and association of signs and symptoms of temporomandibular disorders with missing posterior teeth in adult Jordanian subjects. J Roy Med Serv 2015;22: 23-34.

18. Aiken A, Bouloux G, Hudgins P. MR Imaging of the temporomandibular Joint. Magn Reson Imaging Clin N Am 2012;20: 397-412.

19. Israel HA. Internal derangement of the temporomandibular joint new perspectives on an old problem. Oral Maxillofac Surg Clin Nort Am 2016;28: 313-333.

20. Dipoyono HM. The effect of the number of extracted two-sided posterior mandibular teeth and the use of partial dentures on joint sound. Majalah Kedokteran Gigi 2012;19: 5-8. (In Indonesia)

21. Reissmann DR, Anderson GC, Heydecke G, et al. Effect of shortened dental arch on temporomandibular joint intra-articular disorders. J Oral Facial Pain Headache 2018;32: 329-337.
22. Al-Sharafi MS, Rong ZS, Long XS, et al. Prolonged missing of molar teeth and risk of temporomandibular joint disorders. Int J Dentist Oral Health 2019;5: 1-4.

23. Dwapayanti AN, Parnaadji RR, Kiswaluyo. Relationship between posterior tooth loss and temporomandibular joint clicking based on gender in prosthodontics Clinic of Jember University Dental Hospital. E-Jurnal Pustaka Kesehatan 2016;4: 507-513. (In Indonesia)

24. Hill A, Duran J, Purcell P. Lubricin protects the tempoomandibular joint surfaces from degeneration. Plos one 2014;9: 1-7.

25. Gupta S, Gupta R, RajeevGarg. Partial edentulism and temporomandibular joint disorders. J Dent Med Sci 2014;13: 60-63.

26. Windriyatna, Sugiatno E, Tjahjanti MTE. Effect of loss of maxillary and mandibular posterior teeth on temporomandibular joint disorders (clinical review of angular radiographic inclination of the articular eminence). J Kedokteran Gigi 2015;6: 315-320. (In Indonesia)

27. Tallents RH, Macher DJ, Kyrkanides S, et al. Prevalence of missing posterior teeth and intraarticular temporomandibular disorders. J Prosthet Dent 2002;87: 45-50.

28. Manchikalapudi G, Polasani LR. Correlation between posterior edentulousness and temporomandibular disorder in adult population: a case control study. IAIM 2017;4: 143-150.

29. Mani FM, Sivasubramanian SS. A study of temporomandibular joint osteoarthritis using computed tomographic imaging. Biomed J 2016;39: 201-206.

30. Wiese M, Svensson P, Bakke M, et al. Association between temporomandibular joint symptoms, signs, and clinical diagnosis using the RDC/TMD and radiographic findings in temporomandibular joint tomograms. J Orofac Pain 2008;22: 239-251.

31. Nguyen MS, Saag M, Voog-Oras $U$, et al. Temporomandibular disorder signs, occlusal support, and craniofacial structure changes among the elderly Vietnamese. J Maxillofac Oral Surg 2018;17: 362-371.

32. Bueno CH, Pereira DD, Pattussi MP, et al. Gender differences in temporomandibular disorders in adultpopulational studies: A systematic review and meta-analysis. J Oral Rehabil 2018;45: 720-729.

33. Costa MR, Junior GdRTF, Santos CN. Evaluation of occlusal factors in patients with temporomandibular joint disorder. Dent Press J Orthod 2012;17: 61-68.

34. Gupta SK, Pratibha PK, Bhat KM, et al. Non-replaced mandibular first molars and temporomandibular joint dysfunction. Nepal J Med Sci 2014;3: 57-62.

35. Ginting R, Napitupulu FMN. Clinical symptoms and factors causing temporomandibular joint abnormality in class I occlusion angle. Jurnal Kedokteran Gigi UNPAD 2019;31: 108-119. (In Indonesia)

36. Umniyati $\mathrm{H}$. The prevalence of Temporomandibular Disorder Joint (TMD) and its severity among YARSI University employees. J Dentomaxillofac Sci 2020;5: 82-85.

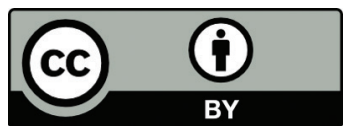

This work is licensed under a Creative Commons Attribution 